\title{
No hallarás timbre en la hospitalaria casa de Arturo Corcuera
}

\author{
You'll Find no Doorbell in Arturo Corcuera's Hospitable House
}

\author{
Edson Faúndez V. \\ Universidad de Concepción, Región del Bio Bio, Chile \\ Contacto: efaundez@udec.cl \\ https://orcid.org/0000-0001-8557-7164
}

\begin{abstract}
Resumen
La escritura poética de Arturo Corcuera (1935-2017) es una de las más relevantes producidas en América Latina entre la segunda mitad del siglo XX y la primera década del siglo XXI. Propongo en este artículo una aproximación crítica al libro A bordo del Arca (2006) a partir del análisis de la relación que se establece entre el sujeto y las cosas. Este análisis, que dialoga con la crítica precedente y utiliza conceptualizaciones teóricas provenientes fundamentalmente del pensamiento filosófico, conducirá a una reflexión sobre los sentidos de la muerte, la amistad y la hospitalidad en la escritura del poeta peruano.
\end{abstract}

Palabras clave: Arturo Corcuera; Lírica latinoamericana; Poesía peruana; Amistad; Objetos.

\begin{abstract}
The poetry of Arturo Corcuera (1935-2017) is one of the most relevant ones produced in Latin America between the second half of the 20th century and the first decade of the 21 st. In this article I propose a critical approach to the book "A bordo del Arca" (2006) from the analysis of the relationship that is established between the individual and things. This analysis, which creates a dialogue with the preceding criticism and uses theoretical conceptions mainly from philosophical thinking, will lead to a reflection on the meanings of death, friendship, and hospitality in the work of the Peruvian poet.
\end{abstract}

Keywords: Arturo Corcuera; Latin American poetry; Peruvian poetry; Friendship, Objects.

Recibido: 27.03 .18

Aceptado: 15.08 .18 


\section{La casa-arca de Arturo Corcuera}

A bordo del Arca (Premio Casa de las Américas, Cuba, 2006) despliega algunas claves que permiten reflexionar sobre los signos distintivos de la escritura de uno de los poetas latinoamericanos más importantes de su generación ${ }^{1}$. La casa, el lugar de la intimidad por excelencia ${ }^{2}$, es cartografiada detalladamente mediante un cuerpo-ojo cautivado y sensitivo. La casa es el territorio donde el sujeto se vuelca sobre sí mismo rodeado de seres vivientes y espectrales, de cosas que lo ligan a otro tiempo y le ofrecen señales de su propia existencia terrenal: una geografía en la que el sujeto deviene en un habitante poseído por presencias tutelares, a las que responde con los gestos de una acogida dulce y amistosa. La casa-arca es también, por eso, el lugar de la superación de la suficiencia del yo y de la transfiguración del recogimiento en una respuesta a "una hospitalidad, a una espera, a un recibimiento humano" (Levinas, 2006, p. 173). La casa es sin duda la que Corcuera edificó en Chaclacayo y al interior de la lengua en la que construyeron su patria César Vallejo y Martín Adán. Esta casa se constituye en un espacio poblado por los vivientes animales y vegetales ${ }^{3}$, huéspedes amables que contribuyen a fracturar la identidad molar del sujeto, quien queda expuesto al incalculable acontecimiento de lo otro. Las alteridades animal y vegetal pueblan los territorios-cuerpos de la casa, del sujeto y de la seductora palabra del poeta, quien aprendió a cantar entre las líneas del desequilibrio.

La poesía de Corcuera puede ser abordada siguiendo las proposiciones de Mario Rodríguez, quien en "La galaxia poética latinoamericana: $2^{\mathrm{a}} \mathrm{mitad}$ del siglo XX” (2002) produce un iluminador mapa de los trayectos de la lírica latinoamericana a partir de la operacionalización de conceptos teóricos desarrollados por Gilles Deleuze y Félix Guattari en Mil mesetas. El crítico chileno plantea que la escritura de Corcuera se posiciona en zonas intermedias, entre los dualismos, donde se actualizan los intensos devenires del yo poético y la legua delirante se transforma en una "pequeña" empresa de salud, capaz de inventar un pueblo de sujetos minoritarios, en función de su distancia respecto de los poderes hegemónicos. En las zonas intermedias fracasan, en efecto, los cortes que organizan reinos, especies, géneros, manadas; entonces la intensidad deseante 
del sujeto ya no puede distinguirse, por ejemplo, de los tordos cantores, de un gato funámbulo o de un gallo con hambre de infinito: “con los tordos, vestidos de luto por una pena, estoy cantando" (2009, p. 27)4, "tengo alma de gato techero" (33), "Me volví gallo: picoteaba las teclas con un dedo, imaginándolas granos de maíz" (67). La casa-arca del poeta transmuta en un espacio profundamente acogedor y hospitalario, lo que se intensifica a partir de su carácter abierto, como lo indica el poema "Mi casa": "Transhumante que llegas a mi casa, no hallarás timbre" (27). Esa es la hipótesis que me impulsa a releer críticamente la poesía de Arturo Corcuera, dispuesta siempre para quien está por venir. La casa-arca despliega una conjura, una invitación: decir algo sobre la significación de las cosas.

\section{Cosas dotadas de vida}

Los sentidos que orbitan la presencia de los objetos en la escritura del poeta peruano no han sido abordados con profundidad por los comentadores de su obra. José Fernández de la Sota, además de destacar el carácter lúdico y el efecto de sencillez que produce la lengua del poeta, señala que "cualquier objeto puede ser poético y cualquier bicho raro se merece embarcar en el arca de Corcuera" (2013, p. 7). Horacio Salas, por su parte, en el prólogo de A bordo del Arca sugiere que este libro "es un volumen que podría calificarse de autobiográfico, pero que sería más justo encuadrar en los marcos de una poética de la memoria, una memoria totalizadora de la experiencia (y de las experiencias) de una vida" (2009, pp. 8-9). Agrega que es relevante "su rescate de los adornos de la casa, muchas veces simples recuerdos de viaje, regalos que acompañan el camino, objetos en los que el poeta deposita sus versos en prueba de agradecimiento por su humilde compañía, esas simples 'cosas' a las que Jorge Luis Borges dedicó un magnífico soneto" (2009, p. 10)5. Acogemos los planteamientos de Fernández de la Sota y de Horacio Salas para someterlos a un desarrollo mayor en este artículo, el cual se constituye en la forma de expresión de mi responsabilidad ante el legado del poeta: la respuesta al llamado silencioso de una lengua que se encumbra hacia regiones cada vez más ajenas a las posibilidades que nos ofrecen nuestras sociedades ultratecnologizadas y refractarias al pacto entre los humanos y las cosas. 
La serie de objetos textualizada en A bordo del Arca ha abandonado su finalidad técnica, su función pragmática, motivo por el que procuraré responder la misma interrogante que se plantea Jean Baudrillard en El sistema de los objetos: "[es necesario dar] respuesta a la pregunta de saber cómo son vividos los objetos [...] en qué sistema cultural, infra o transcultural, se funda su cotidianidad vivida" (2010, p. 2). En la escritura de Corcuera, el desplazamiento de la finalidad técnica trae como correlato una manera distinta de "vivir los objetos" o de vivir en los objetos y dejarse habitar por ellos. Doble movimiento revelador de sentidos que remiten, por ejemplo, a una relación singular con los espectros del ayer, con el tiempo del otro y con los acontecimientos visibles e invisibles que pueblan al sujeto. No enseñan acaso esta situación los siguientes retazos de "Retrato en sepia del rey de los sillones", donde se niegan a desaparecer las memorias del árbol y de sus antiguos habitantes: "aún cantan los pájaros en tu corteza pardo rojiza" (28); de "El poeta y las máscaras", donde la máscara recibe el mismo tratamiento poético (la muerte y la pervivencia en el tiempo del sujeto) dado al viejo sillón de la cita anterior: "alguien oscuro y triste se oculta detrás de cada máscara. Seres tasajeados que vienen inmóviles de mundos desconocidos" (70); y de "El secreto de los baúles", donde la ruta de una travesía vital insiste en el acordado diálogo que se suscita entre el baúl y el sujeto: "en su seno duermen pasajes de mi vida, viajes lejanos, cartas de amor que le escribí a mi amada. Muchos recuerdos y muchas soledades" (34).

Las proposiciones del poeta Rainer María Rilke desplegadas en su carta a Witold Von Hulewicz ${ }^{6}$ se constituyen en otra vía de orientación de esta lectura. Rilke advierte sobre la crisis de una relación de intimidad, poblada de sentidos, entre los humanos y las cosas. La reproducción en serie de las cosas provenientes de la máquina de producción estadounidense dificulta, sin embargo, que estas transmuten en "cosas vividas", por lo que solo pueden ser "cosas vacías, indiferentes, apariencias de cosas... trampas de vida" . Rilke señala, además, que el poeta debe asumir una responsabilidad de incalculable valor: conservar el pacto que reúne al hombre y las cosas. Estamos actualmente enfrentados a la imposibilidad de conjurar el "excedente de sentido" (Bodei, 2013, p. 71) de las 
cosas y de responder al pacto de los antepasados al que alude el poeta de Las elegías de Duino. Ellas han perdido su aura en nuestras sociedades de consumo, como ya lo había advertido Walter Benjamin, quien en este punto dialoga con Rilke, en su ensayo "La obra de arte en la época de su reproductibilidad técnica" $(1936)^{8}$. No ocurre ello en la escritura de Corcuera, legataria del pensamiento poético de Rilke, donde el pacto con las cosas vuelve a emerger.

La transfiguración de los objetos en "cosas dotadas de vida" es una de las claves de comprensión de la escritura del poeta que "no deja de soñar" (85); este se singulariza, entre otros aspectos, por la disolución de las fronteras que separan los ámbitos de lo humano, lo vegetal, lo mineral, lo animal y lo que hay de ellos en "el excedente de sentido" que adquieren las cosas amadas por el bardo. El recurso estilístico de la personificación no es suficiente para hacer visible la relevancia de los objetos que encontramos en poemas como "El fogón y la mesa de los sabores", "Fábula del cuervo oriundo de Ginebra", "Inventario y fábula de los bastones", "Fábula del cajón de los versos perdidos" o "Fábula solar de la sombrerera": "la cuchara espera con la boca abierta, el tenedor enseña sus colmillos rendidos. Su tímida ternura afila el sumiso cuchillo" (54); "Se siente bien cuando me acompaña. En su silencio percibo un hálito de ternura, pero yo sé que en el fondo lamenta su naturaleza de madera. // Él preferiría ser cuervo de carne y hueso y aguardar el momento propicio para sacarme los ojos" (60); "bastones que conocen el secreto de las calles" (71); "En cuanto nos quedamos dormidos los trajes del ropero salen a caminar solos” (83); “¿En qué cabeza soñará el sombrero de paño del abuelo?" (109). Así, la cuchara, el tenedor y el cuchillo establecen un bloque intenso con el sujeto, por lo que el acto de comer se realiza sin el imperio de la autonomía del sujeto: el sujeto entra en las cosas y estas en él: su encuentro hace aparecer la ternura, la misma que invade la relación con el cuervo que aletea en su materialidad. Los bastones, que poseen un saber arcano, los trajes, que aún no olvidan el cuerpo que les dio volumen, y el sombrero del abuelo, que conserva la memoria del hombre soñador: cosas dotadas de vida, cosas que testimonian la alianza con el poeta y con quienes lo preceden.

Remo Bodei propone, en La vida de las cosas, una distinción entre 
"objeto" y "cosa" que resulta pertinente para continuar la reflexión sobre la escritura del poeta peruano. El filósofo advierte:

"Objeto", en cambio, es un término más reciente, que corresponde a la escolástica medieval y parece recalcar teóricamente el griego "problema", "problema" entendido ante todo, como el obstáculo que se antepone para la defensa, un impedimento que, al incorporarse y obstruir el camino, lo cierra y provoca una detención. En latín, más exactamente, el término "obicere" quiere decir "arrojar hacia", "poner por delante".

La noción de objectum (o, en alemán, de Gegenstand, aquello que está delante de mí o en contra de mí) implica por lo tanto un desafío, una contraposición con todo cuanto le impide al sujeto su inmediata afirmación, con cuanto, precisamente, "objeta" sus pretensiones de dominio" [...]. La cosa no es el objeto, el obstáculo indeterminado que tengo frente a mí y que debo abatir o eludir, sino un nudo de relaciones en que me siento y estoy implicado y del que no quiero tener el control exclusivo. (2013, pp. 32-33)

El poeta atesora las cosas con las que establece un incontrolable "nudo de relaciones". Las cosas transmutan en verdaderas arcas sagradas, portadoras - entre otros aspectos - de la memoria de la felicidad y de la alianza con las alteridades que reconfiguran la subjetividad del sujeto. El poeta de $A$ bordo del Arca es responsable del pacto con las cosas que conservan las huellas de vidas, de acontecimientos, de sueños pasados y de ilusiones que abren las esclusas del porvenir. Las cosas nada tienen ya que ver con los objetos insustanciales que proliferan en el contexto de nuestras sociedades de consumo que promueven la reducción de sus posibilidades de sentido ${ }^{9}$. El tejido de relaciones que se articula entre las cosas y los sujetos, entre los sujetos y las cosas, resulta fundamental al momento de interrogarnos sobre los múltiples trayectos, estados y rostros que se despliegan y repliegan en los territorios estéticos que comunican vida y literatura, pues "significados simbólicos, cognitivos y afectivos se cristalizan sobre las cosas (estas no forman un agregado impropio y extrínseco)" (Bodei, 2013, p. 22). Pablo Neruda, poeta del que Arturo Corcuera se siente heredero ${ }^{10}$, ilumina ese complejo "nudo de relaciones" en los versos finales de su conocida "Oda a las cosas" del libro Navegaciones y regresos: "No sólo me tocaron / o las tocó mi mano, / sino que acompañaron / de tal modo / mi existencia / que conmigo existieron / y fueron 
para mí tan existentes / que vivieron conmigo media vida / y morirán conmigo media muerte" (1968, p. 210). El significante tocar presenta una relación marcada por el encuentro compartido entre el sujeto y las cosas, que puede aludir a la importancia de la mano en el nacimiento de las cosas, como bien lo advierte Elías Canetti en Masa y poder:

La mano que recoge agua es el primer recipiente. Los dedos de ambas manos, que se trenzan entre sí, forman la primera canasta. [...] Uno se podría imaginar que los objetos, en nuestro sentido de la palabra, objetos a los que corresponde un valor porque los hemos hecho nosotros mismos, existían primero como signos de las manos [...] Palabras y objetos serían pues emanación y resultado de una única experiencia unitaria, precisamente la de la representación por las manos" (2017, pp. 310-311; énfasis del original)

Palabras y objetos envían, pues, al cuerpo (la mano), que - en el caso de la poesía - se vuelve ingrávido y evanescente cuando se encuentra expuesto al contacto con las alteridades. Los gestos de tocar y de ser tocado se prolongan en el poema de Neruda hacia una forma de vivir donde la configuración de la identidad del sujeto se articula sobre la base de la síntesis entre vida y muerte. No es posible imaginar la escritura y la vida del poeta sin esta consideración fundamental, que también opera en la poesía de Corcuera. La singularidad de la escritura del poeta peruano se expresa, sin embargo, en un nivel distinto a la del poeta chileno, ya que en aquel los trayectos del yo lo instalan insistentemente en una zona de indeterminación entre el sujeto adulto y el sujeto niño. Un devenir niño, en efecto, es el estado que posibilita con más efectividad la emergencia de la voz de las cosas mudas. La alianza con un niño implica involucionar, pero en los términos propuestos por Gilles Deleuze y Félix Guattari: “[...] nosotros preferimos llamar 'involución' a esa forma de evolución que se hace entre heterogéneos, a condición de que no se confunda sobre todo la involución con un regreso. El devenir es involutivo, la involución es creadora" (1997, p. 245). Devenir niño del sujeto adulto y devenir sujeto adulto del niño: alianza creadora que actualiza una dimensión de intercambio donde el sujeto de la enunciación adquiere la posibilidad de contemplar y sentir el mundo con los poderes de la fascinación, 
de los sueños y de la ternura del niño devenido. Un devenir niño posibilita así la energía necesaria para que el encuentro con las cosas genere siempre estados de positividad ${ }^{11} \mathrm{o}$, si seguimos a Bodei, para que se manifieste un incremento de la alegría ${ }^{12}$. De ello deriva también la preferencia de Corcuera por uno de los géneros literarios más antiguos: la fábula. Una es sin duda la dimensión de la fábula privilegiada por Corcuera, la que permite el diálogo entre los animales, las cosas y los seres humanos ${ }^{13}$.

\section{"Mi casa está llena de fantasmas"}

El poema de Neruda, como lo sugerí, alude a la relevancia de las cosas dentro del marco de la inminencia de la muerte propia. La relación profunda que establece Corcuera con la muerte puede advertirse, entre otros aspectos, en el rastro que deja la irrupción de la alianza del poeta y las cosas. La muerte a partir de la segunda mitad del siglo XIX, según Edgar Morin, se caracteriza por la

[...] impotencia de la razón ante la muerte [por lo que] la individualidad hará uso de sus últimos recursos: tratará de conocer a la muerte, no ya por la vía intelectual, sino rastreándola como una alimaña, a fin de penetrar en su madriguera; tratará de rechazarla recurriendo a las más brutas fuerzas de vida. (1974, pp. 297-298)

Phillipe Ariès en Historia de la muerte en Occidente. Desde la Edad Media hasta nuestros días plantea algo similar:

[...] ahora bien, desde hace un tercio de siglo, asistimos a una revolución brutal de las ideas y de los sentimientos tradicionales; tan brutal que no ha dejado de sorprender a los observadores sociales. Es un fenómeno en realidad inaudito. La muerte, en otro tiempo tan presente por resultar familiar, va a difuminarse y a desaparecer. Se vuelve vergonzante y objeto de tabú. (2011, p. 83)

Morin y Ariès hacen evidente el rechazo de la muerte que se actualiza en las sociedades occidentales desde la modernidad hasta nuestros días. Es factible aumentar el número de referencias, provenientes de diversos ámbitos disciplinares, que dan cuenta de los procesos de negación o escamoteo de la muerte que dominan en dichas sociedades, los que terminan por convertir la muerte en 
una cifra estadística (Foucault, 2000), condenar al moribundo a la soledad (Elias, 2009) o someter los signos asociados a la muerte a una higienización escandalosa (Baudrillard, 1993). Pero sean suficientes estas menciones para dibujar un contexto y sugerir que la escritura de los poetas latinoamericanos eminentes se ha convertido en un espacio en donde la muerte resiste los rituales de exorcismo que dominan en el entramado social. Esta constatación hace viable y necesario el análisis de las relaciones profundas que se establecen entre poesía y muerte.

La presencia de la alteridad de la muerte en la escritura literaria envía a un problema de máximo interés. La proximidad del poeta y la muerte encuentra una forma de expresión en la muerte del otro, pues "la muerte, fuente de todos los mitos, sólo está presente en el otro; y solamente en él me llama con urgencia a mi última esencia, a mi responsabilidad" (Levinas, 2006, p. 196). Experiencia que pareciera permitir la reflexión sobre la propia mortalidad y, como consecuencia, el descubrimiento de la fragilidad y vulnerabilidad del sujeto, quien, como todos los vivientes (humanos y no humanos), es también un sujeto muriente. Esta certidumbre, que reúne a una colectividad heterogénea sobre la base de la muerte igualadora, es uno de los basamentos del poema-arca, del poema-casa de hospitalidad; allí se despliega la fábula de un territorio refractario a los límites que impiden el hallazgo de la vida, que se transfigura en responsabilidad ante los difuntos, con quienes el poeta teje una red de amistad: "amigos queridos, bienamados, fríos y horizontales, mis muertos, huéspedes míos que se fueron con las golondrinas y no volverán" (25). El poema "Casa de fantasmas", en el que se ficcionaliza, sin horrores de ningún tipo, el encuentro con los fantasmas y la inclusión futura del sujeto a una comunidad espectral, amplifica lo sugerido en el poema "Mi casa":

Mi casa está llena de fantasmas [...] con ellos convivo, me tropiezo, conversamos abatidos en noches solitarias; / en mi casa hay un fantasma uraño que mora en el espejo y asoma cuando yo me acerco, él sueña que Eros, el de las manos ardientes, no el frío Tanatos, le ordenará los cabellos canos y le besará la frente el día que quede en el lecho dormido para siempre, registrándose como uno más en el gremio de los fantasmas. (131) 
El diálogo con el poema "Bitácora del Arca" es patente: "A visitar los rayos de la Luna salen algunas noches mis muertos, deshilachadas las mortajas [...] Se reúnen mis muertos para platicar de sus fríos, del descascaro de las osamentas, tumbados, desmoronándose en las humedades de la tierra" (155). El poema se convierte en un espacio que acoge a los difuntos amados. El sujeto textual literalmente convive con los espectros del ayer, produciéndose así un intercambio simbólico entre vivos y muertos, el cual, si seguimos a Jean Baudrillard en El intercambio simbólico y la muerte (1992), se encuentra en la actualidad excluido del sistema de relaciones del hombre y de la mujer.

Mario Rodríguez plantea, a propósito de Noé delirante, una idea que resulta fundamental para la lectura que sugiero:

Noé sonámbulo y delirante, Arturo Corcuera ha inventado, como los grandes poetas de la galaxia latinoamericana, un pueblo que no existe, pero que puede venir si logran los poetas desenterrarlo de sus negaciones y traiciones, ya que la literatura como salud y delirio consiste en reinventar una tribu propia. (2002, p. 103)

El "pueblo que no existe" todavía, la tribu fabulada en la escritura poética de Corcuera, reúne hospitalariamente a los difuntos, así como también a los vivientes humanos y no humanos y las cosas "vividas". Remo Bodei señala que "las cosas no son muy distintas de las personas o los animales" (2013, p. 43). Esta indiferenciación se manifiesta en la escritura de Corcuera a partir de la configuración de un bloque intenso, un "nudo de relaciones", que integra todos los elementos constitutivos del cuerpo-poema que conjura la ternura y la amistad. Ese pareciera ser el rasgo distintivo de la casa-arca de la hospitalidad. No es factible, por lo tanto, construir una imagen del sujeto sin considerar sus procesos de desterritorialización y contagio con las alteridades señaladas. El poeta edifica así un espacio al interior del lenguaje, que se proyecta hacia el exterior en su casa de Chaclacayo, donde lo revocado por los poderes que rigen nuestras sociedades de mercado es acogido. Forma del encuentro entre la literatura y la vida, entre la residencia sin localización posible y la otra, la ubicada en Av. Santa Inés 582, Chaclacayo, Lima-8. El sobrio lenguaje del poeta, donde el humor y el juego 
encuentran una vía de expresión, reside muy lejos de las zonas de dominio de la lengua que sirve a los poderosos. Nada tiene que ver la lengua de los devenires niño, de los devenires animales y de la transfiguración de los objetos en cosas dotadas de vida $-\mathrm{y}$ es esa su resistencia, su desviación y su aventura - con esos significantes "erizados de inquina / que babean las hienas al instarnos al odio", denunciados por Oliverio Girondo en "Lo que esperamos" (1999, p. 200); palabras incapaces de hacer surgir la esperanza y el estallido "emocionado" de la vida, como sí ocurre en el poema "Masa" de César Vallejo ${ }^{14}$, otro de los compañeros inevitables en las hospitalarias moradas de la poesía de Corcuera.

La textualización de la muerte permite acceder a una "soberanía" sobre el terror que inspira "esa polilla buscona" (62), esa "buscona más flaca que una top-model" (151) ${ }^{15}$ : la muerte. Además del acontecimiento de la muerte de los otros, de la certidumbre de la propia finitud y del encuentro simbólico con los difuntos, la escritura de Corcuera denuncia la violencia ejercida contra los sujetos afectados por el poder, problema que no es pertinente abordar en este artículo. Si profundizamos en la relación que se expresa entre las cosas y la muerte, resulta imprescindible considerar por lo menos dos poemas. Me refiero a "Los objetos cotidianos y la muerte" y "Fábula de los jarrones Shipibos", de los cuales presento los siguientes fragmentos: "llaves que tiraré al mar el día que me vaya y regrese invisible y se me dé por abrir cajones y traspasar las puertas que me fueron cerradas" (147), "De este suelo se forjó la arcilla que esculpió el torso de los jarrones. Sus ánimas te reciben y te servirán de guía cuando te internes en su fronda misteriosa" (102). El objeto llave, que es entregado al mar, clásica metáfora de la muerte, continuará acompañando al sujeto en la hora de su retorno como espectro invisible, que puede sortear, ahora sí, todos los obstáculos que la vida le deparó. Visión optimista del más allá que se intensifica con la idea de que las cosas son portadoras de la memoria de los espectros del ayer. En efecto, las ánimas de los jarrones elaborados por los Shipibo, etnia de la amazonía peruana, recibirán al sujeto el día de la muerte, que está significada a partir de la metáfora de la "fronda misteriosa". Llama la atención cómo en el primer caso la imagen de la muerte surge de la tradición literaria occidental, mientras que la segunda 
cita remite a la cosmovisión de la etnia Shipibo. Síntesis entre dimensiones heterogéneas que sin duda es clave para comprender el imaginario dominante en la escritura de Corcuera.

El antropólogo Nigel Barley, en Bailando sobre la tumba (2005), investigación en la que se hace visible que la distancia radical entre vivos y muertos es un asunto dominante en las culturas occidentales, advierte:

Existen dos líneas de reflexión habituales en lo que se refiere a posesiones íntimas. Su vinculación con los muertos puede convertirlas en intransferibles reliquias familiares o de otro tipo, conservados por los vivos como testimonios del vínculo entre ellos y los fallecidos. El objeto puede muy bien estar impregnado de estos lazos por obra de la "hermosa pátina que da el uso" tan cara a las casas de subastas. Por otra parte, algunos objetos pueden estar demasiado estrechamente asociados a los fallecidos y han de ser consignados a la tumba, a veces rotos o "muertos", para que aparezcan en el más allá. Robert Hertz, el teórico de la muerte, hace extensivo al propio cuerpo este proceso [Hertz, 1907]. A medida que se descompone en este mundo reaparece en el siguiente. (2005, p. 109)

Las dos líneas de análisis señaladas por Barley confluyen en la escritura de Corcuera en la medida en que los jarrones de los habitantes de la selva se constituyen en cosas que testimonian el vínculo entre muertos y vivos, y en que las llaves se presentan como cosas que acompañarán al difunto en el más allá. En la escritura poética que examino debe tenerse en consideración, sin embargo, que las fronteras entre vivos (el acá) y muertos (el allá) son erosionadas, por lo que ambas dimensiones se traslapan, produciendo los sugerentes intercambios que establece la poesía de Corcuera.

\section{"La hebra de la vida"}

El poema "Bitácora del Arca", el último de A bordo del Arca, presenta, en realidad, una sugestiva abertura en el entramado textual: "Huéspedes míos mis poetas muertos, agarrotados, raídos, crispados solo de pensar que Atropos pudiera cortarles el hilo de la muerte y Cloto tejerles otra vez la hebra de la vida" (162). El texto, que exalta la condición de morada que acoge a los difuntos (los amigos poetas que perviven en los libros) de la casa-poema-arca del poeta, se cierra con la frase "la hebra de la vida", que envía al establecimiento de líneas sueltas, que 
son apertura y espera de los trayectos y las transfiguraciones intensificadoras de la vida. Esa hebra, esa posibilidad de trazar otras líneas de fuga que recuperen la intensidad de la vida, es predominante y esencial en la escritura poética de Arturo Corcuera. Mario Rodríguez ya había apuntado que la poesía del escritor peruano, así como la de Nicanor Parra, Gonzalo Rojas, Juan Gelman, Roque Dalton y Raúl Zurita es "capaz de extraer energía de todo" (2002, p. 97). De extraer energía positiva y proyectarla hacia el porvenir. Por eso sus poemas revelan una resistencia contra los signos de negatividad que pueblan el exterior social, contra "Tanatos de pérfidos ojos" (26), y el sujeto, las palabras, los difuntos, los amigos y las cosas se advierten como una sola intensidad de resistencia contra la muerte. "Retrato en sepia del rey de los sillones", "Fábula del diluvio y el gallo del arca" y "Fábula del gallo sobre la chimenea baldía" iluminan esta relación mediada por las cosas: "ayúdame sillón a luchar contra la muerte" (29), "Y allí está el tornasoleado desafiando con sus espuelas al tiempo y a las tinieblas" (113), “Tú y yo intentemos juntos alejar las oscuridades / y que siempre en nuestras plumas hágase la luz" (132). El poeta escribe para abrir pasajes de vida, para producir artísticamente "hebras de vida", para "alejar las oscuridades" y establecer los territorios de la luz: "Gracias, paredes de mi casa, por protegerme del frío. I Gracias, techo. Gracias, ventanas, por dejar pasar la luz” (84). De este modo el poeta, quien descubre la dulzura hasta en las aguas del mar ${ }^{16}$, despliega su consigna de vida: “iQue el hombre no sea sólo convidado al festín de la última cena para que nos coman los gusanos!” (137).

Elías Canetti (1994), en el discurso "La profesión del escritor", pronunciado en Munich en 1976, señala que el don del escritor es ser custodio de las metamorfosis y que su contribución, aunque frecuente los territorios de la nada y de la tristeza, es siempre incrementar el valor de la vida. La responsabilidad a la que alude Canetti ilumina una ética, que dialoga con lo planteado por Fernando Savater en Invitación a la ética:

El propósito desaforado y sublime de la ética (que ésta rara vez se confiesa a sí misma) es lograr que la muerte muera: es decir, que la implantación de la muerte en la vida, que es el orden vigente en el mundo, sea sustituido por un asentamiento de la vida por encima y 
contra la necesidad de la muerte. (1995, p. 148)

La escritura poética de Arturo Corcuera puede ser interpretada a la luz de los planteamientos de Canetti y de Savater, pues se caracteriza precisamente por una responsabilidad que permite el salto desde una estética particular hacia una ética íntima. Hay algo más, sin embargo, en su poesía que requiere de la sabiduría de otro intercesor. Se trata de Emmanuel Levinas, quien en Totalidad e infinito reflexiona sobre la sensibilidad gozosa y la trascendencia a partir de la donación al otro:

La orientación estética que el hombre da al conjunto de su mundo, representa en un plano superior un retorno al gozo y a lo elemental. El mundo de las cosas llama al arte en el que el acceso intelectual al ser se muda en gozo, en el que lo Infinito en la idea es idolatría en la imagen finita, pero suficiente. (2006, p. 159)

\section{Y agrega:}

La relación con el otro no se produce fuera del mundo, pero pone en cuestión el mundo poseído. La relación con el otro, la trascendencia, consiste en decir el mundo al Otro [...] La trascendencia no es una visión del Otro, sino una donación original. (2006, p. 191)

Mi interpretación del filósofo que nos enseñó que el lenguaje es hospitalidad me permite plantear que la poesía de Corcuera deviene en escritura gozosa, en celebración gozosa de lo que perecerá irremediablemente, en la medida en que fracasa la idea de posesión sobre los objetos, los otros, el mundo y el sí mismo, y se trazan hebras hacia los dominios de Eros, de la amistad, de la ternura, de la responsabilidad. El gozo del mundo de las cosas para que no decante en aumento del egoísmo del yo, además de la desposesión y reconfiguración de la subjetividad del sujeto — que es poseída y habitada por una sed irrefrenable que viene desde el otro- , exige la donación. Arturo Corcuera dona su palabra ("su decir el mundo"). Esa es su primera donación. Pero la verdadera donación, la otra forma de su responsabilidad ante el otro, pareciera residir en la entrega de su pequeño universo construido en la casa-arca de su poesía y de su vida, lo que advierto en el poema liminar de $A$ bordo del Arca, cuyo título es "Mi antiguo y nuevo testamento". El paratexto envía indudablemente a la relación intertextual que se establece entre este libro y Noé delirante, así como al gesto de entrega de 
aquello que podrá ser acogido y gozado por otro; señala también, sin embargo, hacia el uso eclesiástico dado al término latino Testamentum: alianza. Las alianzas (la antigua y la nueva) con los animales, las plantas, los amigos, los difuntos, las cosas y el lenguaje se constituyen así en la materia de su testamento, de su legado, de su donación dirigida al corazón de los vivientes.

Los seres de los reinos animal y vegetal encuentran en la casa del poeta un lugar acogedor; los objetos vividos y los "amigos queridos" se conectan en las evanescentes habitaciones de la casa en donde imperan la amistad, la dulzura y la piedad. La amistad es la fuerza disolvente del orden de la violencia y de la injusticia en la escritura del poeta que escribe "De mar a mar, de nube a nube a comunicarme con los amigos" (96), Noé delirante de la poesía latinoamericana; pero también es la fuerza que crea los puentes que permiten las bodas con las alteridades que deambulan en los paisajes del poema. Arturo Corcuera reitera incesantemente en su escritura que el lenguaje es amistad. Así lo testimonian poemas como "Vallejo en tres instantes", "Memoria de Emilio Adolfo Westphalen, en sus moradas de la vida y la muerte" y "Descubrimiento de parentescos y el escudo de los Sologuren”. Esa es la fuerza que erige la casa-arca que celebra el poema (y es el poema): territorio donde la promesa de una comunidad inexistente pervive: territorio donde los afectados por el odio reciben hospitalidad: territorio donde el poeta se transfigura en sujeto responsable ante la fragilidad del otro.

\section{Notas}

1 Arturo Corcuera integra, en el contexto de la literatura peruana, la llamada Generación del Sesenta. Carlos L. Orihuela destaca algunos rasgos distintivos de esta generación: “[...] la apertura de un período de radicales transformaciones en la poesía peruana se ponía de manifiesto en la renovación temática, en reajustes conceptuales sociopolíticos, en la revisión de los fundamentos positivistas de la historia y el sujeto del discurso, y en la incorporación de modelos textuales de referentes norteamericanos, europeos y la nueva poesía latinoamericana, que en muchos casos y con mucha anticipación venía acusando una metamorfosis similar" (2006, p. 71). Orihuela, además de subrayar el carácter conversacional y polifónico que distingue a los principales exponentes de esta generación, pone especial atención en la presencia de un sujeto poético descentrado que evidencia "la post-colonialidad y la fragmentación del Perú" (2006, p. 72).

2 Así lo sugiere Gaston Bachelard en sus análisis sobre la imaginación material desarrollados en La tierra y las ensoñaciones del reposo (2006). 
3 Las alianzas con la animalidad son significativas en la producción literaria de Arturo Corcuera. Podemos recordar su relevancia, por ejemplo, en Noé delirante (1963), libro que Eduardo Arroyo (2018, p. 6) considera vanguardista en la medida en que en él se expresa el ecologismo, tendencia central de la década de 1960; incluso su presencia en el capítulo "Animales y otras personas" de Vida cantada. Memorias de un olvidadizo (2017), donde el poeta evoca tres amigos animales: el tordo y sus perros Majo y Jasper. El estudio riguroso (aún no realizado) de las alianzas entre el sujeto y la animalidad contribuirá, entre otros aspectos de interés, a precisar la importancia de las alteridades animales en la configuración del yo y en la articulación de la idea de hospitalidad que domina en la poesía de Corcuera.

4 Todas las citas de $A$ bordo del Arca (Lima, 2009) irán acompañadas, de ahora en adelante, solo con el número de página.

5 Horacio Salas se refiere al soneto "Las cosas" de Elogio de la sombra (1969).

6 Estas proposiciones producen un efecto significativo en la poética lárica del escritor chileno Jorge Teillier. Me he referido a este diálogo entre Rilke y Teillier en el capítulo "Jorge Teillier: heredero de las cosas" del libro Teillier crítico (Faúndez, 2014).

7 Copio el fragmento aludido de la carta dirigida a Witold Von Hulewicz: “[...] y esta actividad se encuentra sostenida y apoyada de manera sorprendente por la desaparición, siempre más rápida, de tantas cosas visibles que no pueden reemplazarse. Para nuestros abuelos, una 'casa', una 'fuente', una torre familiar, hasta sus propios vestidos, su abrigo, eran cosas infinitamente más familiares; casi cada cosa era un receptáculo en el cual encontraban algo humano y al que añadían su parte de humanidad. Y he aquí que se acercan a nosotros, venidas de América, cosas vacías, indiferentes, apariencias de cosas, simulaciones de vida... Una casa, en la acepción americana, una manzana americana o una viña de allí no tienen nada de común con la casa, la fruta, el racimo en los cuales habían penetrado la esperanza y la meditación de nuestros antecesores... Las cosas dotadas de vida, las cosas vividas, las cosas admitidas en nuestra intimidad están declinando y ya no pueden ser sustituidas. Nosotros somos quizá los últimos que habrán conocido tales cosas. Sobre nosotros pesa la responsabilidad de conservar, no solamente su recuerdo, (esto sería poco y no sería posible fiarse de él), sino su valor humano y 'lárico' (lárico en el sentido de divinidades tutelares del hogar). La tierra no tiene más solución que la de volverse invisible: en nosotros, que, por una parte de nuestro ser, participamos de lo Invisible, que tenemos al menos una apariencia de participación y que, durante nuestra existencia aquí, debemos aumentar el invisible que ya poseemos; solamente en nosotros puede realizarse esa transmutación íntima y duradera de lo visible en un invisible que no dependa ya del hecho de ser visible o tangible; lo mismo que nuestro propio destino se volverá en nosotros, sin detenerse, más presente e invisible a la vez" (Rilke, 1945, pp. 104-105; énfasis del original).

8 Benjamin escribe: “[...] se puede resumir estos rasgos en el concepto de aura, y decir: lo que se marchita de la obra de arte en la época de su reproductibilidad técnica es su aura. Es un proceso sintomático; su importancia apunta más allá del ámbito del arte. La técnica de reproducción, se puede formular en general, separa a lo reproducido del ámbito de la tradición. Al multiplicar sus reproducciones, pone, en lugar de su 
aparición única, su aparición masiva. Y al permitir que la reproducción se aproxime al receptor en su situación singular actualiza lo reproducido. Estos dos procesos conducen a un enorme trastorno del contenido de la tradición - un trastorno de la tradición que es la otra cara de la crisis y renovación contemporáneas de la humanidad" (2003, p. 44; énfasis del original). Remo Bodei (2013) amplifica los planteamientos de Benjamin respecto del aura de las cosas. El filósofo italiano manifiesta: "[...] desde la perspectiva que he elegido, el aura es, en cambio, la percepción de la 'inasibilidad' y del excedente de sentido de la cosa, que despliega sus contenidos, entregándolos en creciente medida a quien la considera, pero permaneciendo inagotable en su profundidad" (2013, p. 71). Asumo en este artículo la tesis propuesta por Bodei.

9 Remo Bodei escribe: “[...] los múltiples estados de sentido de los que son sucesivamente despojadas [las cosas] cuando se las trata como entidades conocidas o simples valores de uso y cambio" (2013, p. 11). Bodei alude a la pérdida del excedente de sentido de las cosas, característica del modo en que normalmente nos relacionamos con ellas.

10 Evidencia esta observación el poema "América Neruda" de A bordo del Arca, donde Corcuera expresa su admiración por el poeta de "los objetos y frutos humildes": "con Neruda cantaron los tomates, el serrucho, la lagartija, el diente del cachalote [...] Tuvieron voz las locomotoras, el cactus, la cuchara, el mineral, la naranja, el picaflor, la papa, objetos y frutos humildes y sencillos" (103). La crítica especializada también ha informado sobre los vínculos entre la poesía de Corcuera y Neruda. Marcela Valencia Tsuchiya, por ejemplo, en su tesis doctoral "Jorge Pimentel, Hora Zero y el cambio de época en la poesía peruana" destaca que la escritura de Corcuera (y la de César Calvo) se nutre de la poesía de Neruda y de la Generación del 27 (2017, p. 274). Neruda es, con todo, solo uno de los poetas con los que Arturo Corcuera mantiene un fructífero diálogo. Hildebrando Pérez Grande señala la importancia de Vallejo y Eguren en la escritura de Corcuera, a la vez que permite advertir la significación de las voces del pasado (poetas y estilos) en la poesía del escritor peruano: "A caballo entre las resonancias postvallejianas que iluminan sus primeros poemas y la magia permanente de Eguren, la voz de Corcuera ha ido labrando su propio perfil dentro de la rica tradición de la poesía latinoamericana, de tal suerte que su poética nos devuelve al río de los sonetos, los romances, las canciones, las fábulas, los refranes y otras formas discursivas modernas que se revitalizan al conjuro de los hallazgos del siglo XX como el verso libre, el lenguaje onírico y el juego con la página en blanco" (2017, p. 12).

11 Los objetos, como advierte Remo Bodei, pueden adquirir una connotación positiva o negativa de acuerdo con el tipo de relación que establezca con los humanos: “[...] cualquier objeto es susceptible de recibir investiduras y 'desinvestiduras' de sentido, positivas y negativas" (2013, p. 37); "[...] los objetos son transformados en cosas, o son degradados de cosas a entidades indiferentes" (2013, p. 41). Pensemos, por ejemplo, en la escritura del poeta nicaragüense Joaquín Pasos, específicamente en su poema antibelicista "Canto de guerra de las cosas", donde la hegemonía del dolor y de la muerte del hombre por el hombre provoca que las cosas reciban investiduras negativas o pierdan sus investiduras positivas: "he aquí la ausencia del hombre, fuga de carne, de miedo / días, cosas, almas, fuego. / Todo se quedó en el tiempo. Todo se quemó allá 
lejos" (2008, s/p). La misma situación podríamos visualizar en algunos poemas de Residencia en la tierra (1935) de Pablo Neruda, lo que cambiará radicalmente en Odas elementales (1954).

12 Bodei escribe: "[...] si tradujéramos esta última proposición [se refiere a una idea de Spinoza] a un lenguaje más llano, diríamos que cuanto más conozcamos y amemos cada cosa, tanto más conoceremos y amaremos al mundo [...]. Casi como un beneficio colateral, quien contempla las cosas desde esta perspectiva advierte en sí un incremento de la alegría, una expansión de su propio ser, porque se da cuenta de que las cosas no están muertas y de que nosotros formamos parte de la naturaleza que las (y nos) engloba" (2013, p. 155).

13 Sigo en este punto la entrada "Fábula" del Diccionario de retórica y poética de Helena Beristáin (1995, p. 207).

14 El poema de César Vallejo pertenece a España, aparta de mí este cáliz. Sus versos finales son los siguientes: "Entonces todos los hombres de la tierra / le rodearon; les vio el cadáver triste, emocionado; / incorporóse lentamente, / abrazó al primer hombre; echóse a andar...” (1997, p. 475).

15 Respecto de la escritura y la soberanía sobre la muerte, véase El espacio literario de Maurice Blanchot (1969), específicamente el capítulo "La obra y el espacio de la muerte".

16 El poema "Fábula del cajón de los versos perdidos" señala: "En mis sueños hasta las olas del mar son dulces, aprended lágrimas" (83).

\section{Referencias bibliográficas}

Ariès, P. (2011) [1975]. Historia de la muerte en Occidente. Desde la Edad Media hasta nuestros días. Madrid: El Acantilado.

Arroyo Laguna, E. (2018). Testimonio sobre Arturo Corcuera. Boletín Casa Museo José Carlos Mariátegui, (97), 6-7.

Bachelard, G. (2006) [1948]. La tierra y las ensoñaciones del reposo. Ciudad de México: Fondo de Cultura Económica.

Barley, N. (2005) [1995]. Bailando sobre la tumba. Barcelona: Editorial Anagrama.

Baudrillard, J. (1992) [1976]. El intercambio simbólico y la muerte. Caracas: Monte Ávila.

Baudrillard, J. (1993) [1990]. La transparencia del mal. Ensayo sobre los fenómenos extremos. Barcelona: Editorial Anagrama. 
Baudrillard, J. (2010) [1968]. El sistema de los objetos. Ciudad de México: Siglo Veintiuno Editores.

Benjamin, W. (2003) [1936]. La obra de arte en la época de su reproductibilidad técnica. Ciudad de México: Editorial Ítaca.

Beristáin, H. (1995) [1985]. Diccionario de poética y retórica. Ciudad de México: Editorial Porrúa, S. A.

Blanchot, M. (1969) [1955]. El espacio literario. Buenos Aires: Editorial Paidós.

Bodei, R. (2013) [2009]. La vida de las cosas. Buenos Aires: Amorrortu.

Borges, J. L. (1969). Elogio de la sombra. Buenos Aires: Emecé.

Canetti, E. (1994) [1974]: La conciencia de las palabras. Ciudad de México: Fondo de Cultura Económica.

Canetti, E. (2017) [1960]. Masa y poder. Ciudad de México: Alianza Editorial.

Corcuera, A. (2009) [2006]. A bordo del Arca (3a . Ed.). Lima: Fondo de Cultura Económica.

Corcuera, A. (2017). Vida cantada. Memorias de un olvidadizo. Perú: LaMula.

Deleuze, G. y Guattari, F. (1997) [1980]. Mil mesetas. Capitalismo y esquizofrenia. Valencia: Pre-Textos.

Elias, N. (2009) [1982]. La soledad de los moribundos. Ciudad de México: Fondo de Cultura Económica.

Faúndez, E. (2014). “Jorge Teillier: heredero de las cosas”. En Braulio Fernández Biggs y Marcelo Rioseco (eds.), Teillier crítico (pp. 19-30). Santiago de Chile: Editorial Universitaria.

Fernández de la Sota, J. (2013). Arturo Corcuera, poesía navegable. Recuperado de http://www.zurgai.com/archivos/201308/74-6-7.pdf?1

Foucault, M. (2000) [1997]. Defender la sociedad. Buenos Aires: Fondo de Cultura Económica de Argentina.

Girondo, O. (1999). Obra completa (edición crítica coordinada por Raúl Antelo). Madrid: Editorial Universitaria. 
Levinas, E. (2006) [1971]. Totalidad e infinito. Ensayo sobre la exterioridad. Salamanca: Ediciones Sígueme.

Morin, E. (1974) [1970]. El hombre y la muerte. Barcelona: Editorial Kairós.

Neruda, P. (1968) [1957]. Obras completas. Vol. II. Buenos Aires: Editorial Losada.

Orihuela, C. L. (2006). La poesía peruana de los sesenta y setenta: dos etapas en la ruta del sujeto descentrado y la conversacionalidad. Contracorriente, $4(1), 67-85$.

Pasos, J. (2008) [1962]. "Canto de guerra de las cosas". En Julio Valle-Castillo (selección y presentación), Joaquín Pasos. Canto de guerra de las cosas y otros poemas. Ciudad de México: Universidad Nacional Autónoma de México, Dirección General de Difusión Cultural, Dirección de Literatura.

Pérez Grande, H. (2017). El cantoral de Noé. Boletín Casa Museo José Carlos Mariátegui, (97), 12.

Rilke, R. M. (1945) [1923]. Las elegías de Duino (versión, prólogo, notas y apunte bibliográfico de Juan José Domenchina). Ciudad de México: Editorial Centauro.

Rodríguez, M. (2002). La galaxia poética latinoamericana: $2^{\mathrm{a}}$ mitad del siglo XX. Acta literaria, (27), 91-108.

Salas, H. (2009) [2006]. "Una poética de la memoria" [Prólogo]. En Arturo Corcuera, A bordo del Arca (pp. 7-11) (3 $3^{\text {a }}$ Ed.). Lima: Fondo de Cultura Económica.

Savater, F. (1995) [1982]. Invitación a la ética. Barcelona: Editorial Anagrama.

Valencia Tsuchiya, M. (2017). Jorge Pimentel, Hora Zero y el cambio de época en la poesía peruana (tesis doctoral). Instituto de Escritores Latinoamericanos, Hostos Community College/Cuny. Nueva York.

Vallejo, C. (1997) [1988]. Obra poética (edición crítica coordinada por Américo Ferrari). Madrid: Editorial Universitaria. 